\title{
Clinical Study Head and Neck Solitary Extramedullary Plasmacytoma
}

\author{
Bijan Khademi, ${ }^{1}$ Zohreh Zandifar, ${ }^{2}$ Mohammad Mohammadianpanah, ${ }^{3}$ \\ Sayed Hasan Hamedi, ${ }^{4}$ Samira Razzaghi, ${ }^{4}$ Sareh Mahdavi, ${ }^{5}$ and Leila Moaddabshoar ${ }^{4}$ \\ ${ }^{1}$ Shiraz Institute for Cancer Research, Department of Otolaryngology and Head and Neck Surgery, Khalili Hospital, \\ Shiraz University of Medical Sciences, Shiraz 71936-13511, Iran \\ ${ }^{2}$ Student Research Committee, Department of Otolaryngology and Head and Neck Surgery, \\ Khalili Hospital Shiraz University of Medical Sciences, Shiraz 71936-13511, Iran \\ ${ }^{3}$ Colorectal Research Center, Department of Radiation Oncology, Namazi Hospital, Shiraz University of Medical Sciences, \\ Shiraz 71936-13511, Iran \\ ${ }^{4}$ Student Research Committee, Department of Radiation Oncology, Namazi Hospital, \\ Shiraz University of Medical Sciences, Shiraz 71936-13511, Iran \\ ${ }^{5}$ Student Research Committee, School of Dentistry, Shiraz University of Medical Sciences, Shiraz 71447-16699, Iran
}

Correspondence should be addressed to Mohammad Mohammadianpanah; mohpanah@gmail.com

Received 3 April 2013; Accepted 19 December 2013; Published 4 February 2014

Academic Editor: Enver Ozer

Copyright (C) 2014 Bijan Khademi et al. This is an open access article distributed under the Creative Commons Attribution License, which permits unrestricted use, distribution, and reproduction in any medium, provided the original work is properly cited.

Introduction. This study aimed to report the characteristics and treatment outcome of 13 patients with solitary extramedullary plasmacytomas of the head and neck and analytical literature review. Materials and Methods. Nine patients (69\%) were treated with gross surgical resection followed by radiotherapy, three (23\%) were primarily treated with radiotherapy alone, and one ( $8 \%$ ) was treated with surgery alone. Results. There were 3 women and 10 men with the median age of 52 years. Nasal cavity (46\%) and paranasal sinuses $(23 \%)$ were the most common primary sites. After a median follow-up of 28 months, 10 patients are alive and free of disease, one is alive with multiple myeloma, and two died of multiple myeloma. In the literature review the median age was 58 years and male/female ratio was 2.7. Sinonasal tract was the most common primary site. Ten-year local control and progression to multiple myeloma rates were $88 \%$ and $23 \%$, respectively. The 5 - and the 10 -year overall survival rates were 71 and $69 \%$, respectively. Conclusion. Radiation therapy with or without surgery is an effective treatment for patients with head and neck extramedullary plasmacytoma. However, long-term follow-up for detection of local recurrence and progression to multiple myeloma is essential.

\section{Introduction}

Plasmacytoma is a rare malignant tumor of monoclonal proliferation of plasma cells. It includes multiple myeloma that is a generalized disease and solitary plasmacytoma that occurs in a localized site [1]. Solitary plasmacytomas account for approximately $5-10 \%$ of all plasma cell neoplasms and are divided into medullary if developed in bone marrow and extramedullary if originated from soft tissue [1-6]. Solitary extramedullary plasmacytoma (EMP) is an uncommon tumor consisting of $1-2 \%$ of all plasma cell neoplasms $[4,7]$. Eighty percent of EMP arises in head and neck, particularly in the submucosal tissue of the upper aerodigestive tract such as nasal cavity, paranasal sinuses, nasopharynx, pharynx, oropharynx, and larynx [7-9]. These neoplasms typically present in the fifth to seventh decades of life and are 3 times more common in males [7].

Diagnostic evaluation includes history, physical examination, complete blood count, whole skeletal radiographic survey, serum and urine protein electrophoresis and immunofixation, quantitative immunoglobulin levels, urinary protein excretion in 24 hours, in addition to bone marrow aspiration and biopsy. Radiotherapy with or without surgery gives the best local and regional control [10]. However, approximately $50 \%$ of medullary plasmacytomas ultimately progress to multiple myeloma $[6,32]$. The aim of this study was to report the characteristics and treatment outcome of 13 patients with solitary EMPs of the head and neck and a literature review 
TABLE 1: Patient and tumor characteristics and treatment outcome of 13 patients with solitary EMP of the head and neck.

\begin{tabular}{|c|c|c|c|c|c|c|c|}
\hline Case & Age (yr)/sex & Tumor location & Tumor size $(\mathrm{cm})$ & Symptom & Follow-up (month) & Treatment & Dose of RT (Gy) \\
\hline 1 & $21 / \mathrm{F}$ & Nasal cavity & 3.5 & Nasal obstruction & 36 & GTR + RT & 49 \\
\hline 2 & $73 / \mathrm{M}$ & Nasal cavity & 3 & Nasal obstruction & 40 & GTR + RT & 50 \\
\hline 3 & $29 / \mathrm{F}$ & Nasal cavity & 4 & Nasal obstruction & 39 & $\mathrm{GTR}+\mathrm{RT}$ & 50 \\
\hline 4 & $78 / \mathrm{M}$ & Nasal cavity & 3 & Nasal bleeding & 14 & $\mathrm{GTR}+\mathrm{RT}$ & 50 \\
\hline 5 & $42 / \mathrm{M}$ & Nasal cavity & 5.5 & Nasal obstruction & 151 & RT alone & 49 \\
\hline 6 & $52 / \mathrm{M}$ & Nasal cavity & 7 & Nasal obstruction & 15 & $\mathrm{GTR}+\mathrm{RT}$ & 50 \\
\hline 7 & $60 / \mathrm{F}$ & Nasopharynx & 4 & Nasal obstruction & 32 & RTR & 40 \\
\hline 8 & $63 / \mathrm{M}$ & Maxillary sinus & 4.5 & Pain & 33 & RT alone & 50 \\
\hline 9 & $36 / \mathrm{M}$ & Maxillary sinus & 5 & Pain & 26 & $\mathrm{RTR}+\mathrm{RT}$ & 48 \\
\hline 10 & $21 / \mathrm{M}$ & Maxillary sinus & 3.5 & Nasal bleeding & 6 & $\mathrm{GTR}+\mathrm{RT}$ & 50 \\
\hline 11 & $70 / \mathrm{M}$ & Neck soft tissue & 6 & Pain & 28 & RT alone & 40 \\
\hline 12 & $45 / \mathrm{M}$ & Neck L.N. & 5 & Neck mass & 28 & GTR + RT & 45 \\
\hline 13 & $73 / \mathrm{M}$ & Neck L.N. & 4 & Neck mass & 16 & $\mathrm{GTR}+\mathrm{RT}$ & 38 \\
\hline
\end{tabular}

GTR: gross tumor resection, RTR: radical tumor resection, and RT: radiotherapy.

with quantitative summary and analysis of 26 major related studies including 551 cases over the last 20 years.

\section{Methods and Materials}

Thirteen patients diagnosed with solitary EMP of head and neck that were treated and followed up at 2 academic tertiary referral hospitals since 1999-2011 were studied. The study was approved by the Clinical Research Ethics Committee of Shiraz University of Medical Sciences in accordance with The Code of Ethics of the World Medical Association (Declaration of Helsinki) for experiments involving humans. In this study, solitary EMP was defined as a biopsy-proven single area of extramedullary tumor due to clonal plasma cells, normal skeletal survey, normal bone marrow or less than $5 \%$ plasma cell infiltration in the bone marrow aspiration and a bone marrow biopsy specimen with no evidence of plasma cell nodules, the absence of M-protein in serum and/or urine, normal complete blood count, normal serum calcium level, and the absence of related organ or tissue impairment such as renal dysfunction. Patients with small serum $\mathrm{M}$ component and with posttherapy normalized serum levels were not excluded. In addition, Immunohistochemical staining was performed for kappa and lambda light chains in 7 cases. All patients were treated with curative intent. Nine patients (69\%) were treated with gross surgical resection followed by radiotherapy, three $(23 \%)$ were primarily treated with radiotherapy alone, and one (8\%) was treated with surgery alone. The last patient received salvage radiotherapy for local failure one year after primary surgical resection. The median total radiation dose was 49 (range 40-50) GY. Furthermore, in this study we represent a quantitative summary and analysis of pooled data collection of 26 major related studies published between 1998 and 2012 in PubMed including 551 cases.

\section{Results}

There were 3 women and 10 men with the median age of 52 (range 21-78) years. Nasal cavity (46\%) and paranasal sinuses (23\%) were the most common primary sites. The mean tumor size was 4.5 (range $3-7$ ) cm. Nasal obstruction (46\%), pain (23\%), neck mass (15.5\%), and nasal bleeding (15.5\%) were the most common presentations. After a median follow-up of 39.2 (range 6-151) months for surviving patients, 10 patients are alive and free of disease, one is alive with multiple myeloma, and two died of multiple myeloma (Table 1).

The 10 -year local control rate was $89 \%$. The 2-, 5-, and $10-$ year disease free survival rates were $77.8 \%, 64.8 \%$, and $64.8 \%$, respectively. The 2-, 5-, and 10 -year overall survival rates were $88.9 \%, 74.1 \%$, and $74.1 \%$, respectively.

\section{Discussion}

The majority of cases with solitary EMP occur in the head and neck region, although these neoplasms account for less than $1 \%$ of all head and neck tumors [31]. This neoplasm usually occurs in the sixth and seventh decades of life. In the literature review, the median age of 357 patients in 18 studies was 58 (range $47-68$ ) years [3-5, 7, 10-23]. In the present study, the median age of our patients was 52 years, which is within the range reported in the literature. There is a significant sex-specific susceptibility differences to solitary EMP. In all reported series in the literature, men represent a higher proportion of solitary EMP sufferers than women, with a mean male/female ratio of 2.7 (range from 1.5 to 14) in 17 studies including 400 patients (Table 2 ) $[3-5,7,10,11,13,14$, $16-22,24,25]$. In the present study this ratio was 3.3 which is consistent with the average range of the literature review.

Sinonasal tract $(47 \%)$, nasopharynx (15\%), and oral cavity $(10 \%)$ were the most common primary sites for solitary EMP $[3,4,6,7,11,13-26]$. Similarly, sinonasal tract consisted of $69 \%$ of primary sites in our series. Solitary EMP is a 
TABLE 2: Characteristics and treatment outcomes of 565 patients with extramedullary solitary plasmacytoma of the head and neck in 26 reported series and the present study [3-7, 10-30].

\begin{tabular}{|c|c|c|c|c|c|c|c|c|}
\hline Authors (references) & Pts' number & MCPS & $\mathrm{M} / \mathrm{F}$ & Median age & RT dose (Gy) & LC (\%) & PTMM (\%) & OS rate \\
\hline Bachar et al. [24] & 68 & SNT & $41 / 27$ & - & 35 & - & 23 & $76 \%(5 \mathrm{yr})$ \\
\hline Bolek et al. [29] & 10 & - & - & - & 43.2 & 100 & 54 & $80 \%(15 \mathrm{yr})$ \\
\hline Chao et al. [11] & 14 & SNT, NPX & $14 / 0$ & 59 & 45 & 100 & 31 & $54 \%(10 \mathrm{yr})$ \\
\hline Creach et al. [10] & 18 & - & $16 / 2$ & 64 & 50.4 & 100 & 11 & $31-82 \%(5 \mathrm{yr})$ \\
\hline Galieni et al. [12] & 16 & - & - & 54 & - & 92 & 15 & $78 \%(15 \mathrm{yr})$ \\
\hline Hotz et al. [27] & 14 & - & - & - & - & 86 & 14 & - \\
\hline Jyothirmayi et al. [3] & 7 & SNT & $6 / 1$ & 58 & 40 & 85 & 42 & $57 \%$ \\
\hline Kapadia et al. [13] & 20 & SNT, NPX & $16 / 5$ & 59 & $40-45$ & 85 & 20 & $85 \%(10 \mathrm{yr})$ \\
\hline Kilciksiz et al. [14] & 23 & Oral cavity & $14 / 9$ & 47 & 50 & 95 & 17.4 & $89 \%(10 \mathrm{yr})$ \\
\hline Krause et al. [15] & 8 & NPX & - & 61 & 48 & 100 & 25 & 100 (10 yr) \\
\hline Liebross et al. [28] & 19 & - & - & - & 50 & 95 & 44 & $50 \%(5 \mathrm{yr})$ \\
\hline Mendenhall et al. [4] & 20 & SNT, NPX & $17 / 3$ & 62 & $40-50$ & 100 & 30 & $80 \%(5 \mathrm{yr})$ \\
\hline Michalaki et al. [16] & 10 & SNT & $6 / 4$ & 55 & $40-50$ & 100 & 20 & $50 \%(5 \mathrm{yr})$ \\
\hline Miller et al. [17] & 18 & SNT, NPX & $12 / 6$ & 50.4 & $45-50$ & - & 11 & - \\
\hline Ozsahin et al. [26] & 52 & SNT & - & - & 40 & 74 & 36 & $72 \%(5 \mathrm{yr})$ \\
\hline Reed et al. [23] & 23 & SNT & - & 56 & 45 & 92 & 30 & $85 \%(5 \mathrm{yr})$ \\
\hline Sasaki et al. [18] & 67 & SNT & $43 / 24$ & 64 & 50 & 87 & 12 & $56 \%(10 \mathrm{yr})$ \\
\hline Shih et al. [5] & 10 & - & $9 / 1$ & 63 & 54 & 70 & 20 & $100 \%(10 \mathrm{yr})$ \\
\hline Strojan et al. [25] & 22 & Oropharynx & $17 / 5$ & - & 54 & 100 & 8 & $61 \%(10 \mathrm{yr})$ \\
\hline Suh et al. [19] & 13 & SNT & $8 / 5$ & 52 & 50 & 77 & 15 & $87 \%(10 \mathrm{yr})$ \\
\hline Susnerwala et al. [7] & 25 & SNT & $23 / 2$ & 68 & 38.9 & 79 & 8 & $59 \%(5 \mathrm{yr})$ \\
\hline Tournier-Rangeard et al. [21] & 17 & SNT, NPX & $14 / 3$ & 62 & 52.6 & 73 & 31 & $63.4 \%(10 \mathrm{yr})$ \\
\hline Tsang et al. [6] & 14 & SNT, NPX & - & - & 35 & 93 & 84 & $65 \%(10 \mathrm{yr})$ \\
\hline Yang et al. [20] & 23 & SNT & $17 / 6$ & 49 & - & - & - & - \\
\hline Yang et al. [30] & 8 & - & - & - & 35 & - & 12.5 & - \\
\hline Zhou et al. [22] & 12 & SNT & $10 / 2$ & 57 & - & - & - & $53 \%(5 \mathrm{yr})$ \\
\hline Present study & 13 & SNT, NPX & $10 / 3$ & 52 & 49 & 89 & 15 & $74.1 \%(10 \mathrm{yr})$ \\
\hline Total & 564 & SNT & $293 / 108$ & 58 & 44.5 & 88 & 23 & 70 \\
\hline
\end{tabular}

Pts' number: patients number, MCST: most common primary sites, M/F: male/female, LC: local recurrence, PTMM: progressed to multiple myeloma, OS: overall survival, SNT: sinonasal tract, NPX: nasopharynx, LRX: larynx, and NC: nasal cavity.

highly radiosensitive disease and most reports show excellent local disease control and long-term myeloma free survival following radiotherapy alone. A total dose of $40-50 \mathrm{~Gy}$ is recommended by most authors. Surgery may have role in selected cases $[2,3,8,10,11,15,23,24,27,28,31,33]$. The average median total radiation dose used for 499 patients in 22 studies was 44.5 (range 35-52.6) Gy [3-7, 10, 11, 13$19,21,23-26,28-30]$. In the present study, the median total radiation dose was 49 (range 38-50) Gy which is in agreement with the literature.

The 10-year local control rate of our patients was $88.9 \%$, which is consistent with $88 \%$ (range $73 \%-100 \%$ ) for 435 patients in 21 reported series in the literature (Tables 2 and 3 ) $[3-7,10-16,18,19,21,23-28]$. Patients with solitary EMP are at risk of progression and development of multiple myeloma at a rate of $15 \%$ in 10 years (Table 3). Therefore, these patients should be followed up for prolonged period for detecting local recurrence and multiple myeloma [31]. In the literature review, we found an average rate of $23 \%$ progression to multiple myeloma in 10 years for 529 patients in 23 studies $[3-7,10-19,21,23-30]$. The 10-year rate for progression to multiple myeloma in our study was $15 \%$ which is comparable to the literature. This difference may be due to lower followup in our cases compared to most reported series. The 5- and the 10 -year overall survival rates of our patients were $74.1 \%$. In the literature review, the 5 -year overall survival rate was $71 \%$ for 230 patients in 8 studies [4, 7, 10, 16, 22, 23, 26, 28], and the 10 -year overall survival rate was $69 \%$ for 240 patients in 12 studies [5, 6, 11-15, 18, 19, 21, 25, 29].

In a similar study, Alexiou et al. performed a comprehensive literature review and analysis. They searched more than 400 publications between 1905 and 1997 to find all cases with EMP of the head and neck published in the medical literature [31]. In Table 3, we performed a comparison between the results of Alexiou et al. literature review (before 1998) and recent literature published (1998-2012) [6, $10,11,14-24,28,30]$. In addition, we performed a quantitative summary and analysis of these pooled data collection. 
TABLE 3: Comparison of the results of patients with extramedullary solitary plasmacytoma of the head and neck in Aliexiou's et al's literature review [31] with the present study [6, 9, 14-22, 27, 28, 30, 31].

\begin{tabular}{|c|c|c|c|c|}
\hline Variables & Alexiou’s LR (before 1998) [31] & Present LR $(1998-2012)^{\mathrm{a}}$ & Present study & Overall \\
\hline Patients' number & 714 & 345 & 13 & 1072 \\
\hline \multicolumn{5}{|l|}{ Primary sites } \\
\hline Sinonasal tract & $313(44 \%)$ & $163(47 \%)$ & $9(69 \%)$ & $485(45 \%)$ \\
\hline Nasopharynx & $131(18 \%)$ & $51(15 \%)$ & $1(8 \%)$ & $183(17 \%)$ \\
\hline Oral cavity & $22(3 \%)$ & $35(10 \%)$ & $0(0.0 \%)$ & $57(6 \%)$ \\
\hline Oropharynx & $103(15 \%)$ & $26(7.5 \%)$ & $0(0.0 \%)$ & $129(12 \%)$ \\
\hline Larynx & $79(11 \%)$ & $26(7.5 \%)$ & $0(0.0 \%)$ & $105(10 \%)$ \\
\hline Hypopharynx & $4(0.5 \%)$ & $2(0.5 \%)$ & $0(0.0 \%)$ & $6(0.5 \%)$ \\
\hline Salivary glands & $29(4 \%)$ & $4(1 \%)$ & $0(0.0 \%)$ & $33(3 \%)$ \\
\hline Cervical L.N. & $12(1.5 \%)$ & $13(4 \%)$ & $2(15 \%)$ & $27(2.5 \%)$ \\
\hline Orbit & $0(0.0 \%)$ & $13(4 \%)$ & $0(0.0 \%)$ & $13(2 \%)$ \\
\hline Miscellaneous & $16(2 \%)$ & $12(3.5 \%)$ & $1(8 \%)$ & $29(3 \%)$ \\
\hline Local control rate & $78 \%$ & $87 \%$ & $89 \%$ & $81 \%$ \\
\hline Progression to MM rate & $16.1 \%$ & $21 \%$ & $15 \%$ & $17.7 \%$ \\
\hline 5-year OS & $73.3 \%$ & $72.5 \%$ & $74.1 \%$ & $73 \%$ \\
\hline 10-year OS & $68.5 \%$ & $69 \%$ & $74.1 \%$ & $69 \%$ \\
\hline
\end{tabular}

LR: literature review; L.N.: lymph node; MM: multiple myeloma; OS: overall survival.

${ }^{\mathrm{a}}[6,9,14-22,27,28,30,31]$.

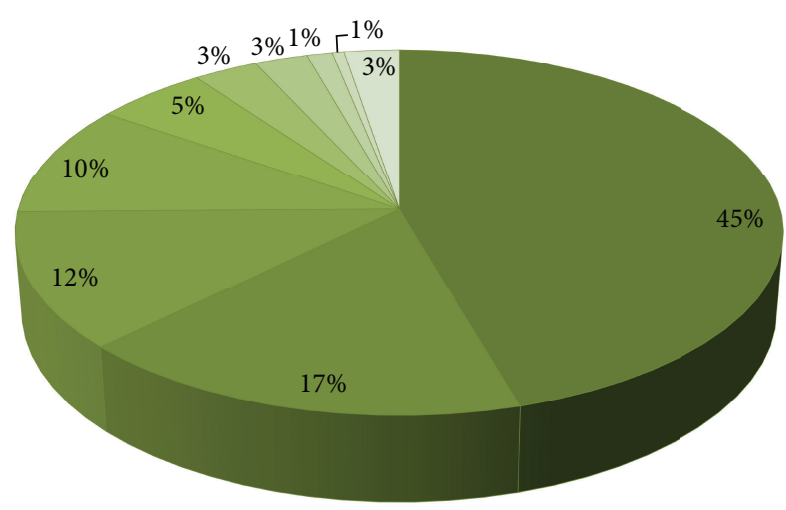

Sinonasal tract $(45 \%)$

Nasopharynx $(17 \%)$

Oropharynx (12\%)

Larynx (10\%)

Oral cavity $(6 \%)$

FIGURE 1: The distribution of primary sites in 1072 patients with EMP in the head and neck in the literature [6, 9, 13-22, 27-29, 31].

Figure 1 represents the distribution of primary sites in 1072 patients with EMP in the head and neck. Accordingly, we found a similar distribution of primary sites and overall survival rates between Alexiou's literature review and recent literature published (1998-2012); however, the rates of local control and progression to multiple myeloma were higher in our review compared to Alexiou's literature review $[6,10,11$, $14-24,28,30,31]$.

\section{Conclusion}

According to the results of the present study and review of the literature and by analyzing the large data collection of recent major reported series, we found that radiation therapy with or without surgery is an effective treatment for patients with head and neck extramedullary plasmacytoma. However, long-term follow-up for detection of local recurrence and progression to multiple myeloma is essential.

\section{Conflict of Interests}

All authors have no conflict of interests to declare.

\section{References}

[1] G. M. Dores, O. Landgren, K. A. McGlynn, R. E. Curtis, M. S. Linet, and S. S. Devesa, "Plasmacytoma of bone, extramedullary plasmacytoma, and multiple myeloma: Incidence and survival in the United States, 1992-2004," British Journal of Haematology, vol. 144, no. 1, pp. 86-94, 2009.

[2] A. R. Harwood, M. A. Knowling, and D. E. Bergsagel, "Radiotherapy of extramedullary plasmacytoma of the head and neck," Clinical Radiology, vol. 32, no. 1, pp. 31-36, 1981.

[3] R. Jyothirmayi, V. P. Gangadharan, M. K. Nair, and B. Rajan, "Radiotherapy in the treatment of solitary plasmacytoma," British Journal of Radiology, vol. 70, pp. 511-516, 1997.

[4] W. M. Mendenhall, C. M. Mendenhall, and N. P. Mendenhall, "Solitary plasmacytoma of bone and soft tissues," American Journal of Otolaryngology, vol. 24, no. 6, pp. 395-399, 2003.

[5] L. Y. Shih, P. Dunn, W. M. Leung, W. J. Chen, and P. N. Wang, "Localised plasmacytomas in Taiwan: comparison between extramedullary plasmacytoma and solitary plasmacytoma of bone," British Journal of Cancer, vol. 71, no. 1, pp. 128-133, 1995. 
[6] R. W. Tsang, M. K. Gospodarowicz, M. Pintilie et al., "Solitary plasmacytoma treated with radiotherapy: impact of tumor size on outcome," International Journal of Radiation Oncology, Biology, Physics, vol. 50, no. 1, pp. 113-120, 2001.

[7] S. S. Susnerwala, J. H. Shanks, S. S. Banerjee, J. H. Scarffe, W. T. Farrington, and N. J. Slevin, "Extramedullary plasmacytoma of the head and neck region: clinicopathological correlation in 25 cases," British Journal of Cancer, vol. 75, no. 6, pp. 921-927, 1997.

[8] R. Bataille and J. Sany, "Solitary myeloma: clinical and prognostic features of a review of 114 cases," Cancer, vol. 48, no. 3, pp. 845-851, 1981.

[9] B. Khademi, A. Moradi, S. Hoseini, and M. Mohammadianpanah, "Malignant neoplasms of the sinonasal tract: report of 71 patients and literature review and analysis," Oral and Maxillofacial Surgery, vol. 13, no. 4, pp. 191-199, 2009.

[10] K. M. Creach, R. L. Foote, M. A. Neben-Wittich, and R. A. Kyle, "Radiotherapy for extramedullary plasmacytoma of the head and neck," International Journal of Radiation Oncology Biology Physics, vol. 73, no. 3, pp. 789-794, 2009.

[11] M. W. Chao, P. Gibbs, A. Wirth, G. Quong, M. J. Guiney, and K. H. Liew, "Radiotherapy in the management of solitary extramedullary plasmacytoma," Internal Medicine Journal, vol. 35, no. 4, pp. 211-215, 2005.

[12] P. Galieni, M. Cavo, G. Avvisati et al., "Solitary plasmacytoma of bone and extramedullary plasmacytoma: two different entities?” Annals of Oncology, vol. 6, no. 7, pp. 687-691, 1995.

[13] S. B. Kapadia, U. Desai, and V. S. Cheng, "Extramedullary plasmacytoma of the head and neck. A clinicopathologic study of 20 cases," Medicine, vol. 61, no. 5, pp. 317-329, 1982.

[14] S. Kilciksiz, O. K. Celik, Y. Pak et al., "Clinical and prognostic features of plasmacytomas: a multicenter study of Turkish Oncology Group-Sarcoma Working Party," American Journal of Hematology, vol. 83, no. 9, pp. 702-707, 2008.

[15] S. Krause, J. Hillengass, H. Goldschmidt, J. Debus, and D. Neuhof, "Radiotherapy of solitary plasmacytoma," Annals of Hematology, vol. 90, no. 9, pp. 1093-1097, 2011.

[16] V. J. Michalaki, J. Hall, J. M. Henk, C. M. Nutting, and K. J. Harrington, "Definitive radiotherapy for extramedullary plasmacytomas of the head and neck," British Journal of Radiology, vol. 76, no. 910, pp. 738-741, 2003.

[17] F. R. Miller, P. Lavertu, J. R. Wanamaker, J. Bonafede, and B. G. Wood, "Plasmacytomas of the head and neck," Otolaryngology, vol. 119, no. 6, pp. 614-618, 1998.

[18] R. Sasaki, K. Yasuda, E. Abe et al., "Multi-institutional analysis of solitary extramedullary plasmacytoma of the head and neck treated with curative radiotherapy," International Journal of Radiation Oncology Biology Physics, vol. 82, no. 2, pp. 626-634, 2012.

[19] Y. G. Suh, C. O. Suh, J. S. Kim, S. J. Kim, H. O. Pyun, and J. Cho, "Radiotherapy for solitary plasmacytoma of bone and soft tissue: outcomes and prognostic factors," Annals of Hematology, vol. 91, no. 11, pp. 1785-1793, 2012.

[20] F. Yang, W. Liu, L. Jiang, F. Li, D. Liao, and G. Li, "Solitary plasmacytoma: a clinicopathologic and immunophenotypic analysis of 43 cases," Journal of Sichuan University, vol. 37, no. 1, pp. 93-144, 2006.

[21] L. Tournier-Rangeard, M. Lapeyre, P. Graff-Caillaud et al., "Radiotherapy for solitary extramedullary plasmacytoma in the head-and-neck region: a dose greater than 45 gy to the target volume improves the local control," International Journal of Radiation Oncology Biology Physics, vol. 64, no. 4, pp. 1013-1017, 2006.
[22] G. Y. Zhou, B. Q. Gao, Y. F. Liu, X. L. Zhang, and J. Q. Wang, "Extramedullary plasmacytoma of the head and neck: a clinicopathologic, immunohistochemistry study," Journal of Clinical Otorhinolaryngology, vol. 14, no. 4, pp. 168-170, 2000.

[23] V. Reed, J. Shah, L. J. Medeiros et al., "Solitary plasmacytomas: outcome and prognostic factors after definitive radiation therapy," Cancer, vol. 117, no. 19, pp. 4468-4474, 2011.

[24] G. Bachar, D. Goldstein, D. Brown et al., "Solitary extramedullary plasmacytoma of the head and neck: long-term outcome analysis of 68 cases," Head and Neck, vol. 30, no. 8, pp. 1012-1019, 2008.

[25] P. Strojan, E. Šoba, J. Lamovec, and A. Munda, "Extramedullary plasmacytoma: clinical and histopathologic study," International Journal of Radiation Oncology Biology Physics, vol. 53, no. 3, pp. 692-701, 2002.

[26] M. Ozsahin, R. W. Tsang, P. Poortmans et al., "Outcomes and patterns of failure in solitary plasmacytoma: a multicenter Rare Cancer Network study of 258 patients," International Journal of Radiation Oncology Biology Physics, vol. 64, no. 1, pp. 210-217, 2006.

[27] M. Hotz, J. Bosq, G. Schwaab, and J. Munck, "Extramedullary solitary plasmacytoma of the head and neck. A clinicopathological study," Annals of Otology, Rhinology and Laryngology, vol. 108, no. 5, pp. 495-500, 1999.

[28] R. H. Liebross, C. S. Ha, J. D. Cox, D. Weber, K. Delasalle, and R. Alexanian, "Clinical course of solitary extramedullary plasmacytoma," Radiotherapy and Oncology, vol. 52, no. 3, pp. 245-249, 1999.

[29] T. W. Bolek, R. B. Marcus Jr., and N. P. Mendenhall, "Solitary plasmacytoma of bone and soft tissue," International Journal of Radiation Oncology Biology Physics, vol. 36, no. 2, pp. 329-333, 1996.

[30] S. Yang, Z. Xiao, S. Wang et al., "Clinical analysis of extramedullary plasmacytomas in the head and neck," Journal of Clinical Otorhinolaryngology, Head, and Neck Surgery, vol. 21, no. 18, pp. 817-819, 2007.

[31] C. Alexiou, R. J. Kau, H. Dietzfelbinger et al., "Extramedullary plasmacytoma: tumor occurrence and therapeutic concepts," Cancer, vol. 85, no. 11, pp. 2305-2314, 1999.

[32] M. Meziane, M. Boulaadas, L. Essakalli, M. Kzadri, and A. Harmouch, "Solitary plasmocytoma: ghost tumour?" International Journal of Oral and Maxillofacial Surgery, vol. 41, no. 1, pp. 17-19, 2012.

[33] S. Kilciksiz, O. Karakoyun-Celik, F. Y. Agaoglu, and A. Haydaroglu, "A review for solitary plasmacytoma of bone and extramedullary plasmacytoma," The Scientific World Journal, vol. 2012, Article ID 895765, 6 pages, 2012. 


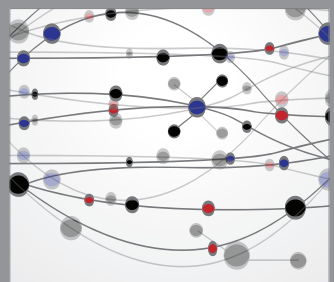

The Scientific World Journal
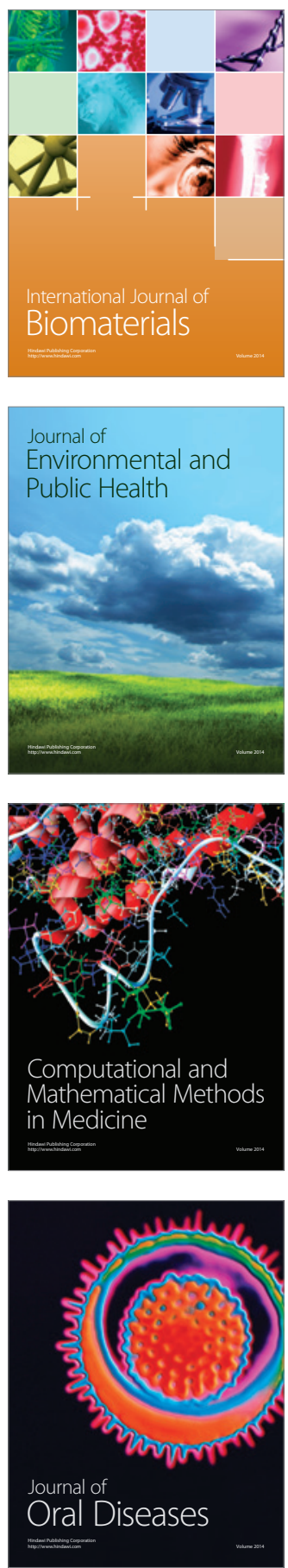
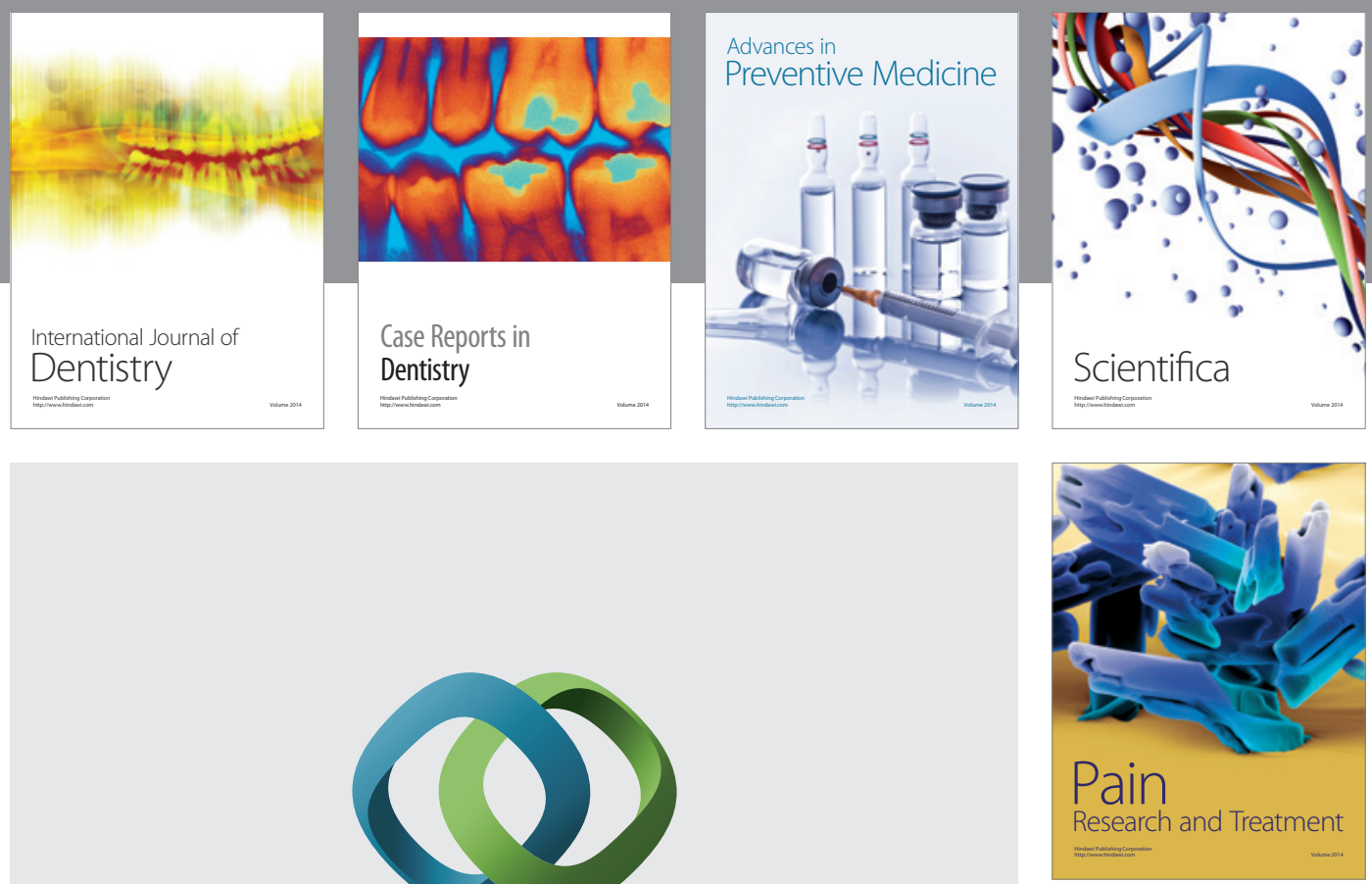

\section{Hindawi}

Submit your manuscripts at

http://www.hindawi.com
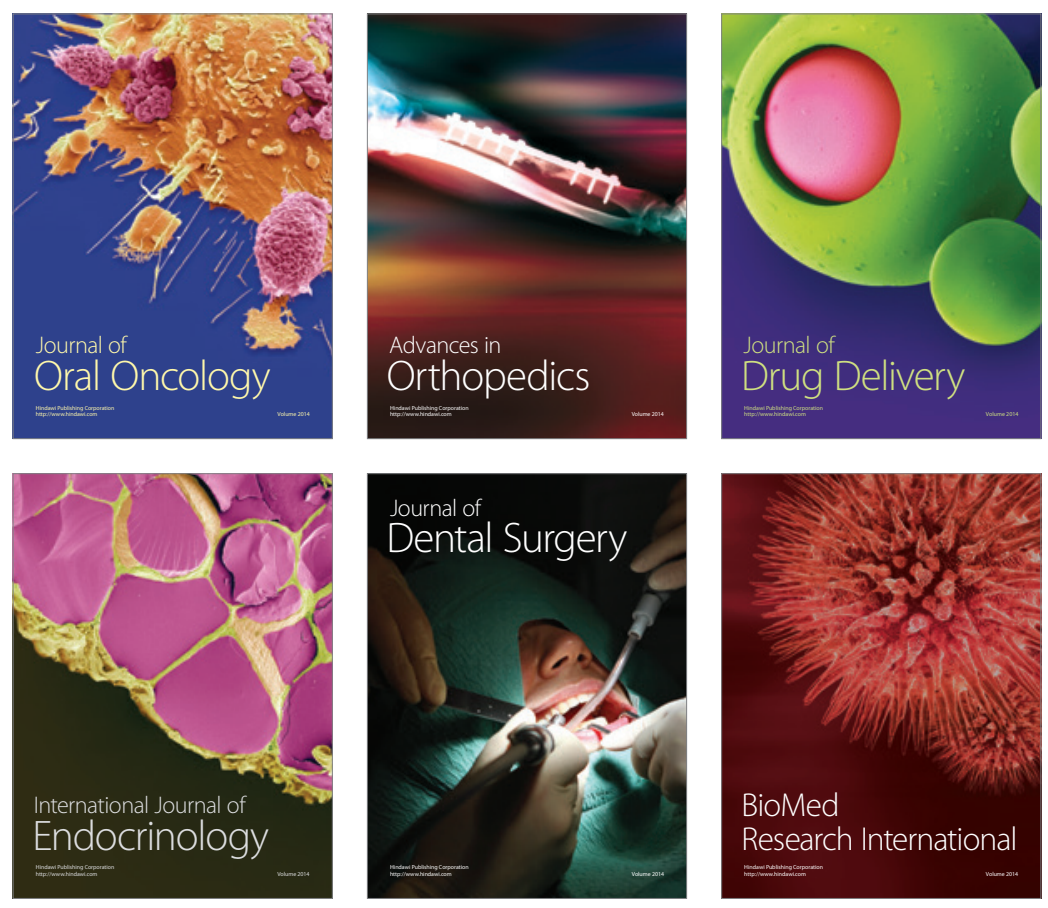

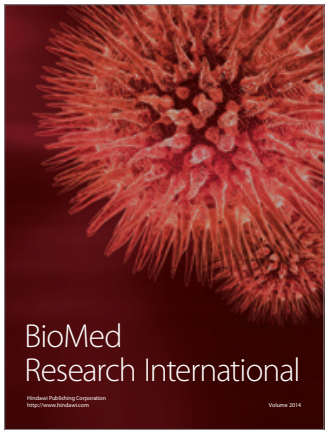

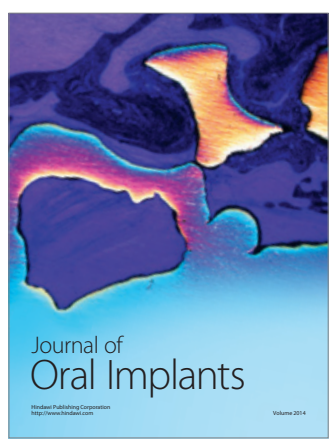
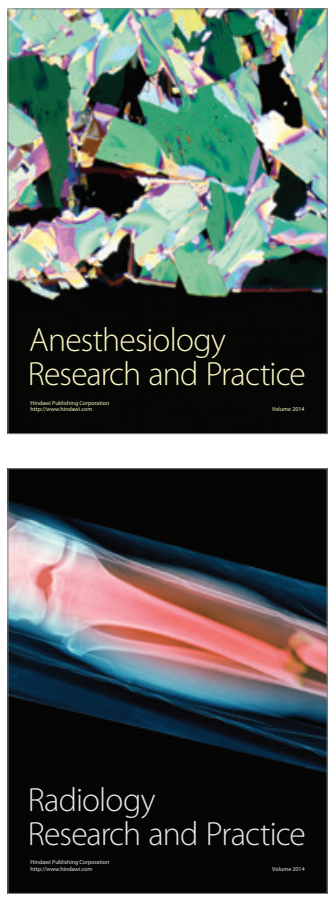